\title{
Temporary loop versus end ileostomy for faecal diversion in ileal perforation: a case matched study
}

\author{
H. Verma, K. Dev, S. Pandey, J. Gurawalia, S. Marwah \\ Pt BD Sharma Post Graduate Institute of Medical Sciences, Rohtak, Haryana, India.
}

Key words: Ileostomy; ileal perforation

\section{Introduction}

The disease ileal perforation is a frequently encountered surgical emergency in developing countries [1]. Typhoid is the most common cause for ileal perforation encountered in developing countries $[1,2]$. Tuberculosis, trauma and nonspecific enteritis follow closely [2].The incidence of perforation in various studies in typhoid fever has been reported to be between $0.8 \%$ to $18 \%$ [3]. The compromised patients of perforation peritonitis due to typhoid fever are best managed with faecal diversion by performing an ileostomy. The other indications of faecal diversion include inflammatory bowel disease, familial adenomatous polyposis, colorectal cancer, non-gastro intestinal obstructing tumours, pelvic sepsis, trauma, diverticulitis, fistula, ischaemic bowel disease, radiation enteritis, pseudomembranous enterocolitis, faecal incontinence and paraplegia [4].

The standard treatment after diagnosis of secondary peritonitis due to hollow viscous perforation is resuscitation followed by laparotomy. The ileal perforation is either closed primarily, or resection and anastomosis of the small bowel is performed, or a diverting stoma is created depending on the site and number of perforations, the severity of peritonitis and the general condition of the patient [5]. The ileostomy serves the purpose of diversion, decompression and exteriorization. A primary ileostomy has been found to be useful in decreasing the morbidity and mortality especially in moribund patients or those with delayed presentation, where it has proved to be a lifesaving procedure [6]. However, ileostomies may result in a significant number of complications as well. The most common complication of ileostomy is peristomal skin irritation leading to skin excoriation, followed by fluid and electrolyte imbalance and nutritional depletion [7]. Other complications post-ileostomy are bleeding, ischaemia, obstruction, prolapse, retraction, stenosis, parastomal hernia, fistula, residual abscess, wound infection and incisional hernia. In addition, an ileostomy is also known to adversely affect the patient's quality of life due to physical restrictions

Correspondence: S. Marwah

E-mail: drsanjay.marwah@gmail.com

DOI: http://doi.org/10.4038/sljs.v34i1.8233 (cc) BY and psychological problems [8].

An ileostomy can be performed as an end ileostomy or loop ileostomy, and both techniques have their own pros and cons. Different authors in the past have compared the results of the two types of ileostomies performed for inflammatory bowel disease and colorectal cancer. Based on their findings, some authors prefer a loop ileostomy whilst others recommend an end ileostomy as a temporary measure for faecal diversion [911]. However, these studies are from western countries and include elective procedures whereas patients with perforation peritonitis present as a surgical emergency and their parameters are entirely different. The temporary diverting ileostomy [end or loop ileostomy] is performed as a life saving measure in such cases and existing literature is silent on comparison of these two procedures in perforation peritonitis.

\section{Materials and methods}

The present study was a prospective case matched clinical study conducted in the Department of Surgery of the Postgraduate Institute of Medical Sciences, Rohtak, over a period of two and half years (August 2011 to December 2013) after getting approval from the institutional ethical committee. Constituency of both the groups were checked from time to time for any gross disparities in the baseline characteristics of the subject.

All the patients presenting in an emergency with perforation peritonitis due to ileal perforation requiring faecal diversion during this period were included in the study. Cases of ileal perforation managed by primary closure of perforation or resection and anastomosis were excluded from the study. The demographic profile of all the patients included in the study was recorded in terms of age, sex, BMI and co-morbidities. All patients received an explanation about the procedure and written consent was taken regarding the stoma formation.

After initial resuscitation, patients underwent an emergency laparotomy through midline incision. The intra-operative findings including the site, number and size of perforation/s, extent of peritonitis, condition of gut, status of lymph nodes and mesentery were recorded, and a thorough peritoneal lavage was done. At the time of stoma creation, a clinical decision was taken to make a loop or end ileostomy by sequential allocation that was created as per standard 
technique. Intra-operative difficulties in stoma creation were recorded. Post-operative recovery was monitored in both groups in terms of appearance of bowel sounds, nasogastric tube removal and the commencement of oral feeding. All early and late post-operative complications were recorded and managed as per standard guidelines.

At the end of the study, data was compiled and subjected to statistical analysis. The qualitative data was analysed using chi-square test and Fisher's exact test whereas quantitative data was analysed by an unpaired t-test. A value of $p<0.05$ was considered significant.

\section{Results}

This case matched study was aimed to compare an end ileostomy with a loop ileostomy performed in cases of perforation peritonitis, in terms of operative difficulty in creating the stoma and post-operative complications.

During the study period, 87 patients were admitted with perforation peritonitis due to ileal perforation and underwent an emergency laparotomy. Forty six out of these 87 cases were excluded from the study as they underwent primary repair of the perforation or were managed with ileal resection and end to end anastomosis. The remaining 41 cases required faecal diversion were included in the study. These cases were divided into group 1 (loop ileostomy) and group 2 (end ileostomy), containing 18 and 23 cases respectively.

\begin{tabular}{|c|c|c|c|c|}
\hline \multicolumn{2}{|r|}{ Particulars } & $\begin{array}{c}\text { Group } 1 \\
\text { Loop ileostomy } \\
\qquad=18\end{array}$ & $\begin{array}{c}\text { Group 2 } \\
\text { End ileostomy } \\
\qquad \mathrm{N}=23\end{array}$ & p value \\
\hline \multicolumn{2}{|c|}{ Mean age } & $34.38+13.39$ & $42.21 \pm 21.03$ & 0.14 \\
\hline \multirow[b]{2}{*}{ Sex } & Male & $16(88.9 \%)$ & $18(78.2 \%)$ & \multirow[b]{2}{*}{0.36} \\
\hline & Female & $02(11.1 \%)$ & $05(21.7 \%)$ & \\
\hline \multicolumn{2}{|c|}{ Mean BMI } & $19.44+1.74$ & $19.77 \pm 1.62$ & 0.53 \\
\hline \multicolumn{2}{|c|}{ Comorbid illness } & 08 (44.4\%) & $10(43.4 \%)$ & 0.95 \\
\hline \multicolumn{2}{|c|}{ TLC $>11000$} & $11(61.1 \%)$ & $11(47.8 \%)$ & 0.39 \\
\hline \multicolumn{2}{|c|}{ Blood Urea $>40$} & $13(72.2 \%)$ & $19(82.6 \%)$ & 0.42 \\
\hline \multicolumn{2}{|c|}{ Positive widal test } & $08(44.4 \%)$ & $07(30.4 \%)$ & 0.35 \\
\hline \multicolumn{2}{|c|}{ Pneumoperitoneum } & $17(94.4 \%)$ & $20(86.9 \%)$ & 0.42 \\
\hline \multicolumn{2}{|c|}{ Preoperative resuscitation (hours) } & $11.83+6.17$ & $10.00+7.51$ & 0.40 \\
\hline
\end{tabular}

Table 1. Demographic profile.

Median age of the study participants were 24 (interquartile range: $21-46)$ years with a male preponderance $(82.9 \%)$. The demographic profile of the patients randomly allotted to group 1 or group 2 were comparable in terms of age, sex, mean BMI, co-morbid illness, clinical, biochemical and radiological profile (Table 1).

Majority of the patients $(46.3 \%)$ required preoperative resuscitation for 7-12 hours. Operative findings in terms of number of perforations, site and size of perforations were comparable in both the groups. All the patients had generalized peritonitis and diffuse enteritis. About 78\% patients had a single perforation in the terminal ileum, measuring $<1 \mathrm{~cm}(75.6 \%)$, and most of them were located within $30 \mathrm{~cm}$ of the ileo-caecal junction (Table 2).

\begin{tabular}{|c|c|c|c|c|c|}
\hline \multirow{2}{*}{ Operative findings } & \multicolumn{2}{|c|}{ Group $1(n=18)$} & \multicolumn{2}{|c|}{ Group $2(n=21)$} & \multirow{2}{*}{ p value } \\
\hline & Number & $\%$ & Number & $\%$ & \\
\hline $\begin{array}{c}\text { Number of } \\
\text { perforations } \\
\text { Single } \\
\text { Multiple }\end{array}$ & $\begin{array}{c}17 \\
1\end{array}$ & $\begin{array}{c}94.4 \\
5.6\end{array}$ & $\begin{array}{c}15 \\
8\end{array}$ & $\begin{array}{l}65.2 \\
34.8\end{array}$ & 0.06 \\
\hline $\begin{array}{c}\text { Size of biggest } \\
\text { perforation (cm) } \\
0-0.5 \\
0.6-1 \\
>1\end{array}$ & $\begin{array}{l}3 \\
9 \\
6\end{array}$ & $\begin{array}{c}16.7 \\
50 \\
33.4\end{array}$ & $\begin{array}{c}8 \\
11 \\
4\end{array}$ & $\begin{array}{l}34.8 \\
47.8 \\
17.4\end{array}$ & 0.38 \\
\hline 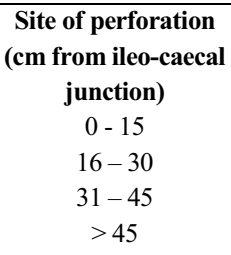 & $\begin{array}{l}5 \\
7 \\
2 \\
4\end{array}$ & $\begin{array}{l}27.8 \\
38.9 \\
11.1 \\
22.2\end{array}$ & $\begin{array}{c}12 \\
6 \\
3 \\
2\end{array}$ & $\begin{array}{c}52.2 \\
26.1 \\
13.0 \\
8.7\end{array}$ & 0.43 \\
\hline
\end{tabular}

Mean (+/- standard deviation) duration of total surgery for loop ileostomy (110.86 +/- 22.94 minutes) was longer in comparison to an end ileostomy (108.33 +/- 18.14 minutes), but the difference was statistically insignificant $(\mathrm{p}=0.49)$. Similarly, mean time taken in making a loop ileostomy (24.26 $+/-6.24$ minutes) was longer than that of an end ileostomy (16.18 +/- 5.12 minutes), but this was not statistically significant $(\mathrm{p}=0.99)$. The stomal delivery was labelled as difficult in cases where excessive traction was required in delivering the gut through the stoma (two finger breadths), necessitating extension of the incision. The stomal eversion was labelled as difficult if sutures were cutting through the gut wall at the time of eversion. During surgery, delivery of the ileal loop through the stoma was found to be difficult in almost half of the cases in the loop ileostomy group due to oedema and congestion of the gut and mesentery. However, in the end ileostomy group, difficult stomal delivery was encountered in only one case $(4.3 \%)$. Difficulty in stomal eversion was almost equal in both the groups (Table 3 ).

Post-operative progression in terms of improvement in abdominal signs, appearance of bowel sounds, stoma functioning and the commencement of oral feeding was comparable amongst the two groups.

In the immediate post-operative period, early complications like stomal discoloration and oedema were seen similarly amongst both the groups and it improved in all the cases with the local application of saline soaked gauge. The occurrence 
of other early complications like high stomal output, dehydration and electrolyte imbalance was also comparable amongst the two groups and was managed with parenteral fluid resuscitation. The electrolyte imbalance in a majority of the cases presented with decreased serum potassium levels $(<3 \mathrm{meq} / \mathrm{L})$ and was managed with intravenous potassium chloride supplementation. Peristomal skin excoriation was seen more commonly in cases of loop ileostomy as compared to end ileostomy, and this difference was found to be statistically significant $(p=0.020)$. The incidence of minor/major wound sepsis, burst abdomen and intraabdominal abscess was comparable amongst the two groups. Late complications like stoma retraction, stoma prolapse, parastomal hernia, stomal stenosis and intestinal obstruction were similar among both the groups. Mean hospital stay $(+/-$ standard deviation) was $8.77+/-4.00$ days in Group-1 and $10.69+/-5.17$ days in Group-2 and the difference was not statistically significant $(p=0.23)$ (Table 4$)$.

\begin{tabular}{|c|c|c|c|}
\hline Difficulty & $\begin{array}{c}\text { Group-1 } \\
\text { Loop ileostomy } \\
(\mathbf{N = 1 8 )}\end{array}$ & $\begin{array}{c}\text { Group-2 } \\
\text { End ileostomy } \\
(\mathbf{N}=\mathbf{2 3})\end{array}$ & P value \\
\hline Difficult stomal delivery & $8(44.4 \%)$ & $1(4.3 \%)$ & $0.002^{*}$ \\
\hline Difficult stomal eversion & $4(22.2 \%)$ & $5(21.7 \%)$ & 0.97 \\
\hline
\end{tabular}

Table 3. Intra-operative difficulty during stoma creation.

(*statistically significant using Fisher's exact test)

\begin{tabular}{|c|c|c|c|c|c|c|}
\hline \multirow{2}{*}{\multicolumn{2}{|c|}{ Complications }} & $\begin{array}{r}\text { Gro } \\
\text { Loop il } \\
\text { (n }\end{array}$ & & $\begin{array}{r}\text { Gro } \\
\text { End i } \\
(n\end{array}$ & $\begin{array}{l}-2 \\
\text { tomy }\end{array}$ & \multirow[t]{2}{*}{ p value } \\
\hline & & Number & $\%$ & Number & $\%$ & \\
\hline \multicolumn{2}{|c|}{ Stomal discoloration } & 3 & 16.7 & 3 & 14.3 & 0.32 \\
\hline \multicolumn{2}{|c|}{ Stomal edema } & 13 & 72.2 & 13 & 56.5 & 0.30 \\
\hline \multicolumn{2}{|c|}{ Skin excoriation } & 11 & 61.1 & 6 & 26.1 & $0.02^{*}$ \\
\hline \multirow{2}{*}{$\begin{array}{l}\text { Wound } \\
\text { sepsis }\end{array}$} & Major & 9 & 50 & 7 & 30.4 & \multirow[t]{2}{*}{0.42} \\
\hline & Minor & 4 & 22.2 & 6 & 26.1 & \\
\hline \multicolumn{2}{|c|}{ Prolapse } & 2 & 11.8 & 3 & 14.3 & 0.81 \\
\hline \multicolumn{2}{|c|}{ Intestinal obstruction } & 5 & 29.4 & 2 & 9.5 & 0.11 \\
\hline
\end{tabular}

Table 4. Early and late post-operative complications.

\section{Discussion}

Perforation of bowel leading to the contamination of an otherwise sterile peritoneal cavity by infection, is often the aetiological cause [12]. The causative factors of perforation in tropical countries contrasts with that of western countries. While upper gastrointestinal tract perforations account for the majority of cases in India, lower tract perforations are the commoner cause in western countries [1].

In patients with ileal perforation surgery is accepted as the definite treatment. However the exact operative procedure to be performed remains the subject of controversy. Simple closure of a single perforation, and resection and anastomosis in the case of multiple perforations remains the favoured choice recommended in most series. These procedures seem appealing, especially in the emergency setting. However these are not free of morbidities, with faecal fistula remaining the most feared consequence with potential for causing mortalities. Its incidence is approximately $12 \%$ and is associated with a very high mortality [13]. Therefore, there has been a tendency to favour a defunctioning protective ileostomy at the site of perforation in recent years. Ileostomy is considered to be a life-saving procedure, particularly in cases with fulminant enteritis and peritonitis of a long standing duration.

The formation of a stoma is one of the easiest bowel procedures for a practicing surgeon; however, complications such as peristomal skin excoriation, electrolyte imbalance, leakage, prolapse, parastomal hernia and retraction are the consequences of poor surgical technique. Moreover, use of a defunctioning stoma can also lead to an impaired QOL, need for readmission to hospital and increased morbidity and mortality due to the stoma and its subsequent closure [14].

An ileostomy to function optimally, should protrude atleast a minimum of $1.5 \mathrm{~cm}$ from the abdominal wall. This is easily achieved with an end ileostomy whilst in a loop ileostomy it may be technically demanding [15]. In our study, the stoma delivery was difficult in $44.4 \%$ cases because of a thickened, oedematous mesentery and severe enteritis. However, in the end ileostomy group, difficult stomal delivery was encountered in only one case $(4.3 \%)$ and the difference was statistically significant $(p=0.02)$. This was the possible reason for taking a longer time in creating a loop ileostomy in comparison to an end ileostomy in the present study. However, this problem is not encountered in an elective stoma creation as the gut wall and mesentery are healthy and nonoedematous.

Data derived from numerous studies showed that the most common stomal complication was para-stomal skin excoriation ranging from 5.9 to $43.8 \%$ in a loop ileostomy and 8 to $34 \%$ in an end ileostomy (Table 5) [10, 16-22]. In the present study, the incidence of skin excoriation was much 
higher in the loop ileostomy group $(61.1 \%)$ than in the end ileostomy group (26.1\%) and this difference was statistically significant $(\mathrm{p}=0.02)$. The difference encountered is probably due to a higher stoma appliance leakage in loop ileostomies as we have to cut it wider to accommodate two barrels of ileum. In an end ileostomy however, the opening made in the stoma appliance is smaller and better fitting because it has to cover only a single barrel of small intestine. The cost of ileostomy care has also been reported to be more than twice of that for a loop ileostomy patient in comparison to an end ileostomy patient [16].

The reported incidence of wound sepsis following a loop ileostomy is $5.8-26.6 \%$ in various studies whereas there is only one report of an end ileostomy with wound infection in $10.2 \%$ of cases (Table 5) [1, 10, 17, 20, 22]. In the present study also, the incidence of wound sepsis was much higher in the loop ileostomy group (72.2\%) in comparison to the end ileostomy group $(56.6 \%)$, but this difference was not statistically significant $(p=0.42)$. This was probably due to the higher stoma appliance leakage and faecal soiling of the wound in loop ileostomy cases. Poor general condition, malnutrition and weak immunity were also a contributing factor to poor wound healing and increased chances of wound sepsis in both the groups.

Electrolyte imbalance is common in the early post-operative period following ileostomy because of the large amount of electrolyte-rich effluent. Electrolyte imbalance has been observed in 2.4 - 17\% loop ileostomy cases in various studies (Table 5) [1, 10, 19 - 22]. Its incidence however was much higher in the present study; $33.3 \%$ in loop ileostomy and $26.1 \%$ in end ileostomy cases $(\mathrm{p}=0.61)$, with the majority of cases affected by hypokalaemia. It is possibly because in the present study, most of the cases in both groups had intense enteritis leading to excessive fluid and electrolyte loss through the stoma.

The incidence of stomal bleeding is reported to be 1.8 to $6 \%$ in various studies in cases undergoing loop ileostomy (Table 6) $[10,17-19,22]$. In the present study, none of the patients in either group developed stomal bleeding or necrosis, though a few patients had stomal oedema in the early post-operative period and it was managed with saline soaked gauze and glycerine application locally. Stomal necrosis observed in various studies ranged from $0.58 \%$ to $3.3 \%$, but none of the patients in our study had this complication.

In the past, delayed post-operative complications have been recorded following a loop ileostomy by the majority of the studies conducted, but only a few studies have been done on end ileostomies. No study has compared the two types of ileostomies with regard to the occurrence of post-operative complications. In various studies stomal prolapse was seen in

\begin{tabular}{|c|c|c|c|c|c|c|c|c|c|c|c|}
\hline \multirow{3}{*}{$\begin{array}{l}\text { S. } \\
\text { No. }\end{array}$} & \multirow{3}{*}{$\begin{array}{c}\text { Study } \\
\text { (number of } \\
\text { patients) }\end{array}$} & \multicolumn{10}{|c|}{ (\%) of patients } \\
\hline & & \multicolumn{2}{|c|}{ B leeding } & \multicolumn{2}{|c|}{ Necrosis } & \multicolumn{2}{|c|}{$\begin{array}{c}\text { Skin } \\
\text { excoriation }\end{array}$} & \multicolumn{2}{|c|}{$\begin{array}{l}\text { Electrolyte } \\
\text { imbalance }\end{array}$} & \multicolumn{2}{|c|}{$\begin{array}{c}\text { Wound } \\
\text { infection }\end{array}$} \\
\hline & & G p 1 & Gp 2 & Gp 1 & G p 2 & G p 1 & G p 2 & G p 1 & Gp 2 & Gp 1 & Gp 2 \\
\hline 1 & $\begin{array}{l}\text { Leong et al* } \\
1994^{16} \\
(\mathrm{n}=150)\end{array}$ & - & - & & 1 & - & 34 & - & - & - & - \\
\hline 2 & $\begin{array}{l}\text { Jhobta et al } \\
2006^{1}(\mathrm{n}=92)\end{array}$ & - & - & - & - & - & - & 17 & - & 25 & - \\
\hline 3 & $\begin{array}{l}\text { Muneer et al } \\
2007^{10} \\
(\mathrm{n}=170)\end{array}$ & 1.8 & - & 0.58 & - & 17.6 & - & 5.81 & - & 5.8 & - \\
\hline 4 & $\begin{array}{l}\text { Rajput et al } \\
2007^{17}(\mathrm{n}=61)\end{array}$ & 6 & - & - & - & 21 & - & - & - & 26.6 & - \\
\hline 5 & $\begin{array}{l}\text { A ziz et al } \\
2009^{18} \\
(\mathrm{n}=112)\end{array}$ & 5.3 & - & - & - & 21.4 & - & - & - & - & - \\
\hline 6 & $\begin{array}{l}\text { Sher-uz-zman } \\
\text { et al } 2011^{19} \\
(\mathrm{n}=46)\end{array}$ & 3 & - & - & - & 22 & - & 6 & - & - & - \\
\hline 7 & $\begin{array}{l}\text { Patil et al } \\
2012^{20}(\mathrm{n}=30)\end{array}$ & - & - & 3.3 & - & 13.3 & - & 6.6 & - & 20 & - \\
\hline 8 & $\begin{array}{l}\text { A li et al }{ }^{\#} \\
2012^{17}(\mathrm{n}=85)\end{array}$ & - & - & - & - & 5.9 & - & 2.4 & - & - & - \\
\hline 9 & $\begin{array}{l}\text { Chun et al* } \\
2012^{22} \\
(\mathrm{n}=123)\end{array}$ & 2.4 & - & 2.4 & - & 42.3 & - & 10.6 & - & 6.4 & - \\
\hline 10 & $\begin{array}{l}\text { Present study } \\
(\mathrm{n}=41)\end{array}$ & - & - & - & - & 61.1 & 26.1 & 33.3 & 26.1 & 72.2 & 56.5 \\
\hline
\end{tabular}

Table 5. Early complications of an ileostomy.

(Gp 1: Loop ileostomy group, Gp 2: End ileostomy group. * Ileostomy done electively for colorectal cancer, polyposis coli, Inflammatory Bowel Disease. \#- type of stoma not mentioned) 
2.9 to $8 \%$ of loop ileostomy cases, whilst Carlsen and Bergan observed it in $1.8 \%$ cases of end ileostomies (Table 6 ) [10, 16, $19,21]$. The incidence of stomal prolapse was much higher in the present study, consisting of $11.8 \%$ in the loop ileostomy group and $14.3 \%$ in the end ileostomy group. The higher incidence of prolapse was possibly due to malnutrition, sepsis and post-operative cough which was seen in many cases in the present study.

The reported incidence of stoma retraction is $1.2-5.3 \%$ following a loop ileostomy and $2.7-17 \%$ following an elective end ileostomy (Table 6) [10, 18, 19, 21 - 23]. In the present study, none of the patients had stomal retraction after a loop ileostomy, but $9.5 \%$ of cases had stomal retraction after an end ileostomy ( $\mathrm{p}=0.19)$. One of our patients with end ileostomy also suffered a stomal retraction due to weight gain. Another patient had excessive skin excoriation secondary to stomal retraction and required an early stoma reversal.

The reported incidence of stomal stenosis is $1.0-4.0 \%$ following a loop ileostomy and $10.3 \%$ following an end ileostomy (Table 6) [10, 16, 19, 21, 22], however no cases in either group of the current study developed stomal stenosis.

The reported incidence of parastomal hernias is $0.9-2.94 \%$ following a loop ileostomy, and as high as $16 \%$ after an end ileostomy in various studies in the past [10, 19, 22, 23]. In our present study however, no case from either group developed parastomal hernias as a delayed complication of stoma creation.

Bowel obstruction after ileostomy creation is relatively common, affecting up to $25 \%$ of ileostomy patients during their lifetime. Frequently, these episodes correspond to a food bolus obstruction proximal to the terminal portion of the small bowel or secondary to an adhesive band. Most patients respond to non-operative management. If the patient seems haemodynamically compromised, with signs of sepsis or peritonitis, laparotomy is mandatory to release the band obstruction and maintain blood supply [25]. Small bowel obstruction is reported to be seen in $0.94 \%$ to $10.5 \%$ of loop ileostomy cases. Leong et al observed 23\% incidence of obstruction in end ileostomy [16]. Our experience in loop ileostomies revealed obstruction in $29.4 \%$ of patients whilst only $9.5 \%$ of cases had post-operative intestinal obstruction after an end ileostomy; the difference however was not statistically significant $(\mathrm{p}=0.11)$. The possible reason for a higher incidence of post-operative adhesive intestinal obstruction could be the presence of generalized peritonitis in majority of the cases.

\section{Conclusion}

In conclusion, a temporary de-functioning protective ileostomy in moribund cases of peritonitis due to ileal perforation is a lifesaving procedure. Apart from reducing the mortality, it plays a vital role in decreasing the incidence of complications like faecal fistula formation. The faecal

\begin{tabular}{|c|c|c|c|c|c|c|c|c|c|c|c|}
\hline \multirow[t]{2}{*}{$\begin{array}{c}\text { Study } \\
\text { Number }\end{array}$} & \multirow[t]{2}{*}{ Study } & \multicolumn{2}{|c|}{ Prolapse } & \multicolumn{2}{|c|}{ Retraction } & \multicolumn{2}{|c|}{ Stenosis } & \multicolumn{2}{|c|}{$\begin{array}{c}\text { Parastomal } \\
\text { hernia }\end{array}$} & \multicolumn{2}{|c|}{$\begin{array}{l}\text { Small bowel } \\
\text { obstruction }\end{array}$} \\
\hline & & $\begin{array}{c}\text { Gp } \\
1 \\
(\%)\end{array}$ & $\begin{array}{c}\text { Gp } \\
2 \\
(\%)\end{array}$ & $\begin{array}{c}\text { Gp } \\
1 \\
(\%)\end{array}$ & $\begin{array}{c}\text { Gp } \\
2 \\
(\%)\end{array}$ & $\begin{array}{c}\text { Gp } \\
1 \\
(\%)\end{array}$ & $\begin{array}{c}\text { Gp } \\
2 \\
(\%)\end{array}$ & $\begin{array}{c}\text { Gp } \\
1 \\
(\%)\end{array}$ & $\begin{array}{c}\text { Gp } \\
2 \\
(\%)\end{array}$ & $\begin{array}{c}\text { Gp } \\
1 \\
(\%)\end{array}$ & $\begin{array}{c}\text { Gp } \\
2 \\
(\%)\end{array}$ \\
\hline 1 & $\begin{array}{c}\text { Leoong et al } \\
1994^{16}(\mathrm{n}=150)\end{array}$ & 8 & - & - & 17 & 04 & - & - & 16 & - & 23 \\
\hline 2 & $\begin{array}{c}\text { Muneer et al } \\
2007^{10}(\mathrm{n}=170)\end{array}$ & 2.94 & - & 3.5 & - & $\begin{array}{c}1.1 \\
7\end{array}$ & - & 2.94 & - & - & - \\
\hline 3 & $\begin{array}{l}\text { Aziz et al } \\
2009^{18} \\
(\mathrm{n}=112)\end{array}$ & - & - & 5.3 & - & - & - & - & - & - & - \\
\hline 4 & $\begin{array}{l}\text { Ali et al } 2010^{23} \\
\quad(\mathrm{n}=106)\end{array}$ & - & - & 1.8 & - & - & - & 0.94 & - & 0.94 & - \\
\hline 5 & $\begin{array}{l}\text { Sher-uz-zman } \\
\text { et al } 2011^{19} \\
(\mathrm{n}=46)\end{array}$ & 5 & - & 4 & - & 1 & - & 3 & - & - & - \\
\hline 6 & $\begin{array}{c}\text { Ali et } a l^{\#} \\
2012^{21}(\mathrm{n}=85)\end{array}$ & 3.5 & - & 1.2 & - & 2.3 & - & - & - & - & - \\
\hline 7 & $\begin{array}{c}\text { Chun et al } \\
2012^{22}(\mathrm{n}=123)\end{array}$ & - & - & 1.2 & - & 1.2 & - & 4.8 & - & 2.4 & - \\
\hline 8 & $\begin{array}{l}\text { Present study } \\
\quad(\mathrm{n}=41)\end{array}$ & 11.8 & 14.3 & - & 9.5 & - & - & - & - & 29.4 & 9.5 \\
\hline
\end{tabular}

Table 6. Delayed Complications of Ileostomy.

(Gp 1: loop ileostomy, Gp 2 : end ileostomy. * Ileostomy done electively for colorectal cancer, polyposis coli, Inflammatory Bowel Disease. \# - type of stoma not mentioned) 
diversion can be performed by an end ileostomy or loop ileostomy. During creation of a loop ileostomy, stomal delivery is difficult due to oedema and inflammation of the gut and adjoining mesentery. Moreover in the post-operative period there is problem of ill- fitting stoma bags for loop ileostomy cases leading to faecal soiling and a high incidence of parastomal skin excoriation that is relatively difficult to manage. Hence an end ileostomy is found to be more effective in managing such cases. Further studies of a larger magnitude of ileal perforation peritonitis cases would be required to substantiate the results of the present study.

All authors disclose no conflict of interest. The study was conducted in accordance with the ethical standards of the relevant institutional or national ethics committee and the Helsinki Declaration of 1975, as revised in 2000 .

\section{References}

1. Jhobta RS, Attri AK, Kaushik R, Sharma R, Jhobta A. Spectrum of perforation peritonitis in India -review of 504 consecutive cases. World J EmergSurg [internet] 2006 [cited 2014 Feb 18] [4p] available from: http://www.wjes.org/content/1/1/26.

2. Hussain T, Alam SN, Salim M. Outcome of ileostomy in cases of small bowel perforation. PakJ Surg. 2005;21:65-71.

3. Edino ST, Yakubu AA, Mohammed AZ, Abubakar IS. Prognostic factors in typhoid ileal perforation: a prospective study of 53 cases. JNational Med Assoc. 2007;99:1042-5.

4. Ashraf I, Muammad G, Noon RS, Mohammad A, Haider H, Abid KJ. To compare the outcome of ileostomy versus primary repair in enteric perforation. PakJ Med Health Sci. 2010;4:523-5.

5. Wittmann DH, Schein M, Condon RE. Management of secondary peritonitis. Ann Surg. 1996;224:110-8. http://dx.doi.org/10.1097/00000658-199607000-00003

6. Bashir M, Nadeem T, Iqbal J, Rashid A. Ileostomy in typhoid perforation. Ann KE Med coll. 2003;9:221-5.

7. Ajao OG. Typhoid perforation: factor affecting mortality \& morbidity. J Int Surg. 1982;67:317-9.

8. Malik AM, Laghari AA, Mallah Q, Qureshi GA, Talpur AH, Effendi S, et al. Different surgical options and ileostomy in typhoid perforation. World JMed Sci. 2006;1:112-6.

9. Ekenze SO, Okoro PE, Amah CC, Ezike HA, Ikefuna AN. Typhoid ileal perforation: analysis of morbidity and mortality in 89 children. Niger J ClinPract. 2008;11:58-62.

10. Muneer A, Shaikh AR, Shaikh GA, Qureshi GA. Various complications in ileostomy construction. World ApplSci J. 2007;2:190-3.

11. Hallbook O, Mathiessen P, Leinskold T, Nystrom PO, Sjodahl R. Safety of temporary loop ileostomy. Colorectal Dis. 2002;4:3614. http://dx.doi.org/10.1046/j.1463-1318.2002.00398.x

12. Williams NS, Bulstrode CJK, O'Connell PR. Bailey \& Love's Short Practice of Surgery. 26th edition. Boca Raton: CRC press Taylor\& Francis group; 2013. p. 970-86.
13. Khan AA, Kha IR, Najeeb U, Shaikh AJ. Comparison between primary repair and exteriorization in cases of typhoid perforation. Ann KE Med coll.2005;11(3):226-7.

14. Tsunoda A, Tsunoda Y, Narita K, Watanabe M, Nakao K, Kusano M. Quality of life after low anterior resection and temporary loop ileostomy. Dis Colon Rectum. 2008;51:218-22. http://dx.doi.org/10.1007/s10350-007-9101-7

15. Fonkalsrud EW, Thakur A, Roof L. Comparison of loop versus end ileostomy for fecal diversion after restorative proctocolectomy for ulcerative colitis. J Am Coll Surg. 2000;190:418-22. http://dx.doi.org/10.1016/S1072-7515(99)00295-1

16. Leong APK, Schimmer EEL, Phillips RKS. Life-table analysis of stomal complications following ileostomy. $\mathrm{Br} J$ Surg. 1994;81:127-9. http://dx.doi.org/10.1002/bjs.1800810536

17. Rajput A, Samad A, Khanzad TW. Temporary loop ileostomy: Prospective study of indications and complications. Rawal Med J. 2007;32:159-62.

18. Aziz A, Sheikh I, Jawid M, Alam SN, Saleem M. Indications and complications of loop ileostomy. PakJ Surg. 2009;14(3):128-31.

19. Sher-uz-Zaman M, Hameed F, Atiq-ur-Rehma S, Khan Y. Loop ileostomy: complications in cases of enteric perforation. Professional MedJ. 2011 Apr-Jun;18(2):222-7.

20. Patil V, Vijayakumar A, Ajitha MB, Kumar SL. Comparison between Tube Ileostomy and Loop Ileostomy as a Diversion Procedure. ISRN Surgery. 2012;5:112-7. http://dx.doi.org/10.5402/2012/547523

21. Ali MZ, Munir K, Zaffar A, Anwar MI. Surgical audit of Emergency Ileostomies. JRMC. 2012;16(1):45-7.

22. Chun LJ, Haigh PI, Tam MS, Abbas MA. De-functioning loop Ileostomy for pelvic anastomoses: predictors of morbidity and non-closure. Dis Colon Rectum. 2012;55:167-74. http://dx.doi.org/10.1097/DCR.0b013e31823a9761

23. Ali SA, Memon M, Ahuja P, Soomro AG, Tahir SM, Shaikh NA. A prospective audit of post-operative complication of construction of loop ileostomy. Medical channel. 2010 Jan-March;16(1):1758 .

24. Kaidar-Person O, Person B, Wexner SD. Complications of construction and closure of temporary loop ileostomy. J Am Coll Surg. 2005 Nov;201(5):759-73.

http://dx.doi.org/10.1016/j.jamcollsurg.2005.06.002

25. Martin ST, Vogel JD. Intestinal stomas indications, management, and complications. Adv Surg. 2012;46:19-49. http://dx.doi.org/10.1016/j.yasu.2012.04.005

26. Martinsson ES, Josefsson M, Ek AC. Working capacity and quality of life after undergoing an ileostomy. $J A d v$ Nurs. 1991;16(9):1035-41. http://dx.doi.org/10.1111/j.1365-2648.1991.tb03363.x

27. Morowitz DA, Kirsner JB. Ileostomy in ulcerative colitis: A question-naire study of 1,803 patients. Am J Surg. 1981;141:3715. http://dx.doi.org/10.1016/0002-9610(81)90199-9

28. Pemberton JH. Management of conventional ileostomies. World J Surg. 1988;12:203-10. http://dx.doi.org/10.1007/BF01658055 